\title{
Near surface geophysical archaeological prospection at the prehistoric site of Akrotiri on Santorini/Thera
}

Immo Trinks ${ }^{1}$, Panagiotis Tsourlos ${ }^{2}$, Klaus Löcker ${ }^{1}$, George Vargemezis², Gregory Tsokas ${ }^{2}$, Andreas Vlachopoulos ${ }^{3}$, Christos Doumas ${ }^{4}$, Matthias Kucera ${ }^{1}$, Geert Verhoeven ${ }^{1}$, Wolfgang Neubauer ${ }^{1}$

${ }^{1}$ Ludwig Boltzmann Institute for Archaeological Prospection and Virtual Archaeology, Vienna, Austria

${ }^{2}$ Aristotle University of Thessaloniki, Department of Geophysics, Thessaloniki, Greece

${ }^{3}$ University of Ioannina, Department of Archaeology, Ioannina, Greece

${ }^{4}$ University of Athens, Department of Archaeology, Athens, Greece 


\section{Introduction}

Near surface geophysical prospection methods can offer the possibility to efficiently investigate buried archaeological remains without disturbing the subsurface (Gaffney \& Gater 2003). Preconditions for a successful survey are favourable circumstances in regard to surface morphology, geology, the physically measureable contrast between archaeological target structure and the surrounding medium, as well as the depth of burial. Most commonly used methods in archaeological prospection are magnetometry, earth resistance measurements and ground penetrating radar surveys.

Some 3600 years ago the Bronze Age settlement of Akrotiri on the Greek island of Santorini/Thera has been covered under thick layers of volcanic pumice by the massive eruption of the Thera volcano. Since 1967 archaeological excavations under the late Prof. Spyridon Marinatos and since 1975 Prof. Christos Doumas have revealed the archaeological remains of an affluent prehistoric society, living in up to three storey high buildings richly decorated with vivid frescoes and sophisticated sewer systems.

So far three buildings have been excavated completely, and circa seven buildings have been partly uncovered in an area measuring approximately $90 \times 120 \mathrm{~m}$ (Doumas 1983). Since 1975 the main focus of the archaeological activities, aside of the restoration of the frescoes, has been the construction of a protective shelter over the excavated architecture. Archaeological excavation at Akrotiri inevitably exposes the archaeological remains and often fragile prehistoric architecture to the risk of destruction in case of stronger seismic events, which are highly likely to occur in one of the world's seismically most active regions (Chouliaras et al. 2012), being located on an active volcano. Additionally, gradual decay caused for example mud wasps and accidents threaten exposed architecture at Akrotiri.

Since it is impossible to prevent partial or total destruction of the excavated architecture in case of a larger earthquake, this unique cultural heritage site has been digitally documented in very high resolution using laser scanning and latest photogrammetric methods. Within this from the Conservation Trust of the National Geographic Society supported project, additionally geophysical archaeological prospection techniques have been tested in the vicinity of the archaeological site of Akrotiri in order to evaluate their potential to map still buried archaeological remains without exposing them to the risk of destruction, being enclosed by volcanic ashes since they last saw the light of day.

With exception of the location Kokkino Vouno (Red Mountain) west of the archaeological site, all other nearby areas are covered by more or less thick layers of volcanic ash and pumice, rendering the application of standard near surface geophysical archaeological prospection approaches challenging. We present background, methodology and results of the in February 2014 at Akrotiri conducted near surface geophysical prospection pilot study.

\section{Methods}

The volcanic geology and the mostly large distance between the surface and the target structures renders the use of the otherwise commonly used magnetic prospection method little promising. Early magnetic prospection measurements were conducted in the area by Dr. Elizabeth Ralph from the University Museum in Philadelphia in 1967 using a Cesium magnetometer, still prior to the substantial archaeological discoveries made by Spyridon Marinatos (Mavor 1969). However, the magnetically highly inhomogeneous volcanic subsurface prevented any positive results. Even sledge hammer seismic measurements for archaeological prospection have been attempted at that time, yet without any great success (Vermeule 1967).

Ground Penetrating Radar (GPR) measurements were to our knowledge first attempted at Akrotiri by Gregory Tsokas and colleagues in September 1996 (The Thera Foundation 1996) using a $225 \mathrm{MHz}$ 
PulseEkko antenna as well as an EPRIS system from Coleman research. The published results indicate limited signal penetrating depths between two and three metres in case of the $225 \mathrm{MHz}$ PulseEkko, thus not yet reaching layers containing antiquities. However, these test conclude that GPR can be successfully used if the alluvium layer, which is the medium causing greatest signal loss, is removed,

Further GPR tests conducted at Akrotiri by Russel and Stasiuk (2000) using a PulseEkko 100 system and 50 and $100 \mathrm{MHz}$ antennae with large trace stacking numbers (256 respectively 128) resulted in reflectors successfully mapped at depths as large as $22 \mathrm{~m}$.

Geoelectrical tomography test has as well been conducted by Toskas and colleagues in 1996 (The Thera Foundation 1996), resulting in the mapping of a resistive layer between two higher conductive ones, possibly imaging the volcanic basement at $6 \mathrm{~m}$ depth.

In February 2014 we tested several GPR antennae systems in the vicinity of Akrotiri, including a shielded $80 \mathrm{MHz}$ MALA Geoscience GroundExplorer prototype antenna, as well as unshielded $100 \mathrm{MHz}$, and shielded $250 \mathrm{MHz}$ and $500 \mathrm{MHz}$ PulseEkko Pro antennae.

Additionally, Electric Resistance Tomography (ERT) measurements using a 48 channel ABEM Terrameter system and sledge hammer seismic refraction measurements employing a 24-channel Geometrics StrataView recorder and P-wave geophones were conducted.

We were able to map for the first time substantial new archaeological structures in the vicinity of the excavation site using high resolution GPR and ERT measurements. On the top of the Red Mountain, where a trial excavation conducted by Prof. Marinatos in 1968 and surface finds of fresco fragments had indicated remains of Bronze Age architecture, two adjacent buildings have been located, as well as a further circular structure of circa $12 \mathrm{~m}$ diameter with uncertain dating.

\section{Conclusions}

We were able to map for the first time substantial new archaeological structures in the vicinity of the archaeological excavation site of Akrotiri using high resolution GPR and ERT measurements. On the top of the Red Mountain, where a trial excavation conducted by Prof. Marinatos in 1968 and surface finds of fresco fragments had indicated remains of Bronze Age architecture, two nearby buildings have been located, as well as a further circular structure of circa $12 \mathrm{~m}$ diameter with uncertain dating. State-of-the-art non-invasive near surface geophysical prospection has the potential to generate important new archaeological information about this fascinating archaeological site. The circumstances pose a challenge due to the thick ash cover.

\section{Acknowledgements}

The digital documentation of Akrotiri including the geophysical prospection pilot study has involved the project partners Prof. Clairy Palyvou and Prof. Maurizio Forte. The geophysical fieldwork has been made possible and conducted by the authors as well as by the $\mathrm{PhD}$ candidates Eamonn Baldwin, Joris Coolen, Ulrike Fornwagner, Manuel Gabler, Martin Gamon, Viktor Jansa, Jakob Kainz, Michal Rus, Petra Schneidhofer, Tomas Tencer, Katalin Tolnai, Willem Vletter, and Mario Wallner from the Initiative College for Archaeological Prospection from Vienna University. This work has been partially funded through an Exploration Grant provided by the Conservation Trust of the National Geographic Society as well as by the Ludwig Boltzmann Institute for Archaeological Prospection and Virtual Archaeology (http://archpro.lbg.ac.at), which is an Institute of the Austrian Ludwig Boltzmann Gesellschaft (http//www.lbg.ac.at). MALÅ Geoscience kindly provided an $80 \mathrm{MHz}$ GroundExplorer antenna system and Dr. Sirri Seren from the Central Institute for Meteorology and Geodynamics Vienna provided the seismic system and unshielded PulseEkko antennae. 


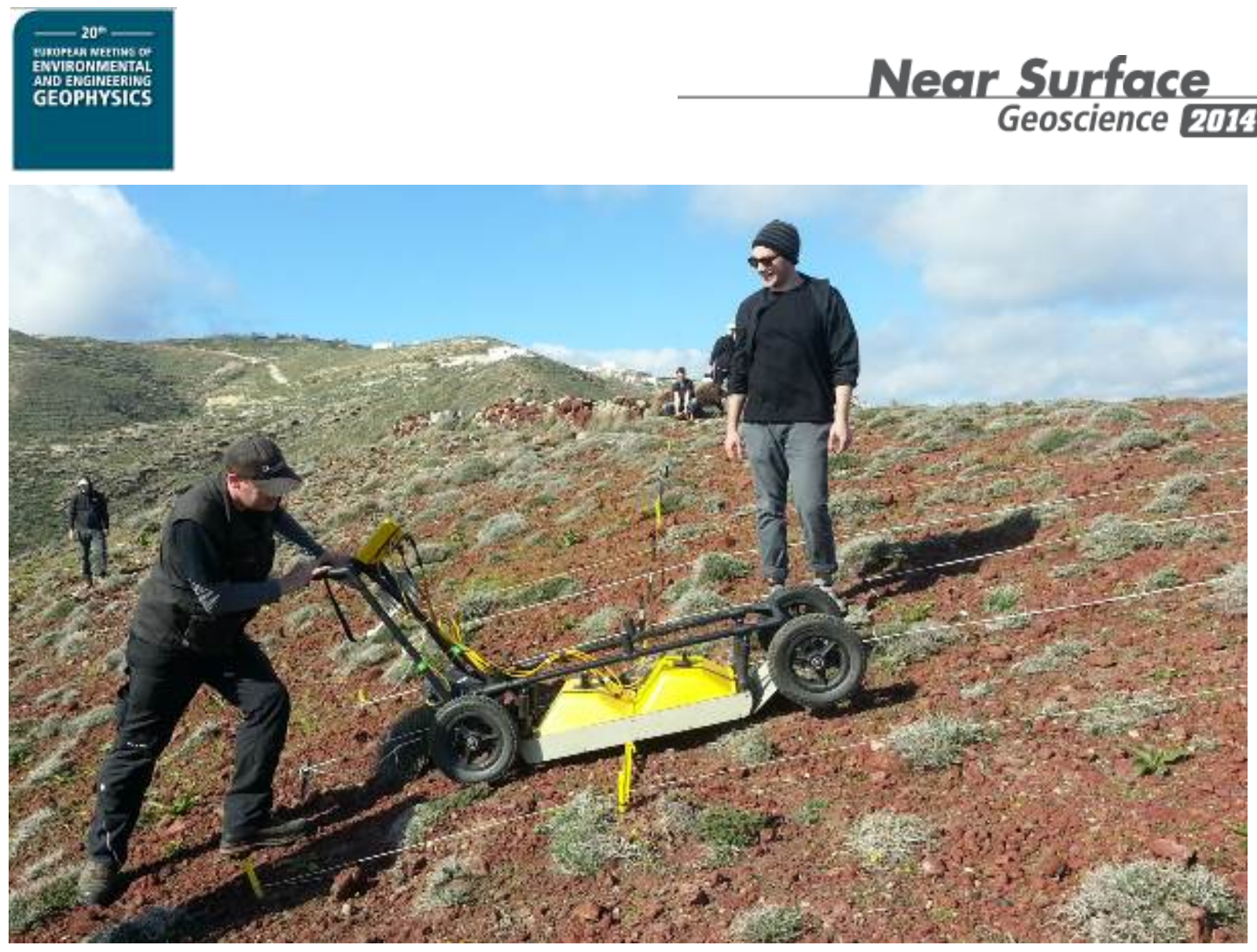

Figure 1 Ground penetrating radar measurements with a $250 \mathrm{MHz}$ antenna system and $25 \mathrm{~cm}$ profile spacing on top of Kokkino Vouno (Red Mountain) near the archaeological site of Akrotiri. Photo: Klaus Löcker.

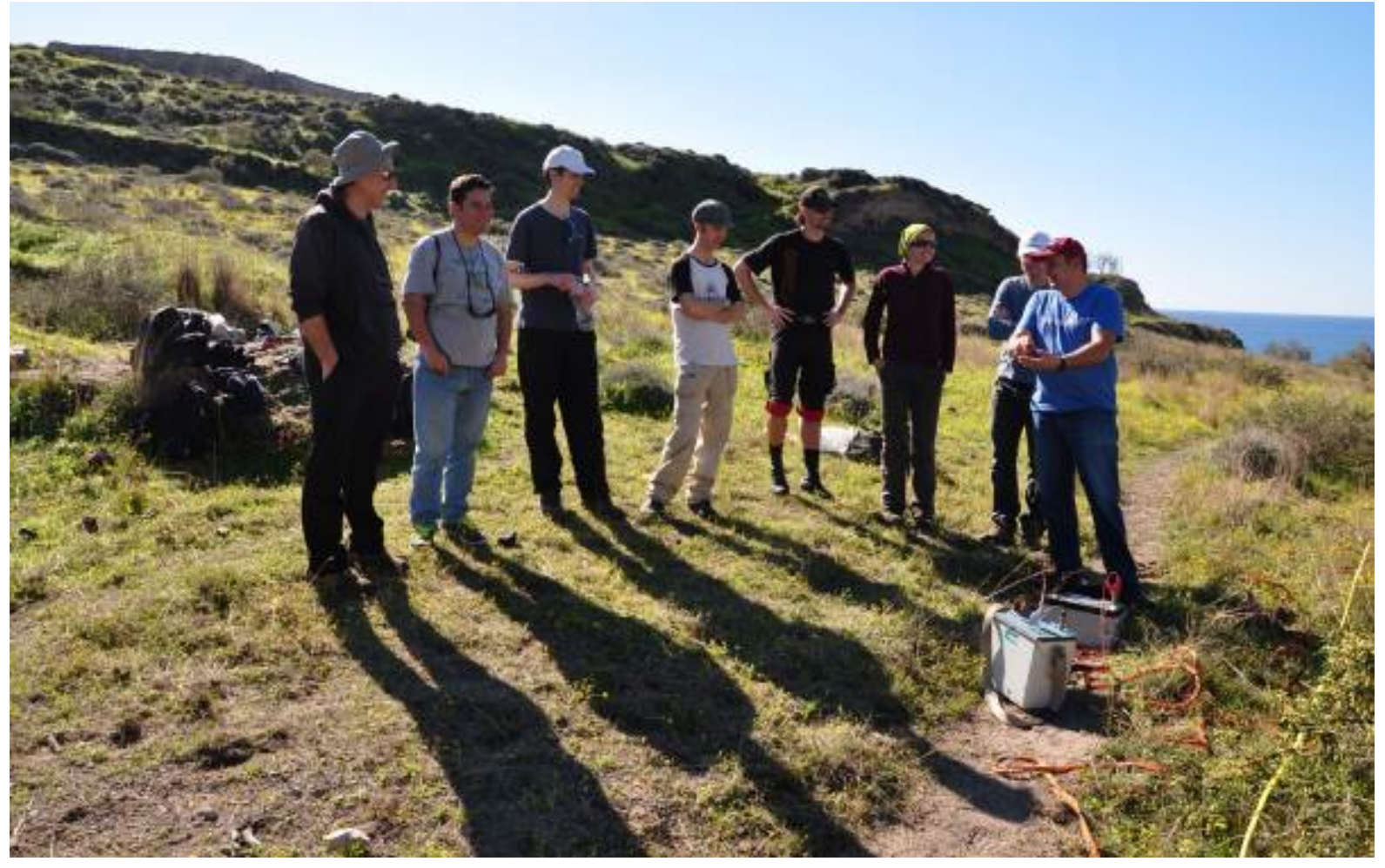

Figure 2 Prof. Tsokas, Prof. Vlachopoulos and PhD students from Vienna listening to Prof. Tsourlos explaining the Electric Resistance Tomography survey method in Potamos valley east of the archaeological site of Akrotiri next to an assumed prehistoric chamber grave. Photo: Immo Trinks. 

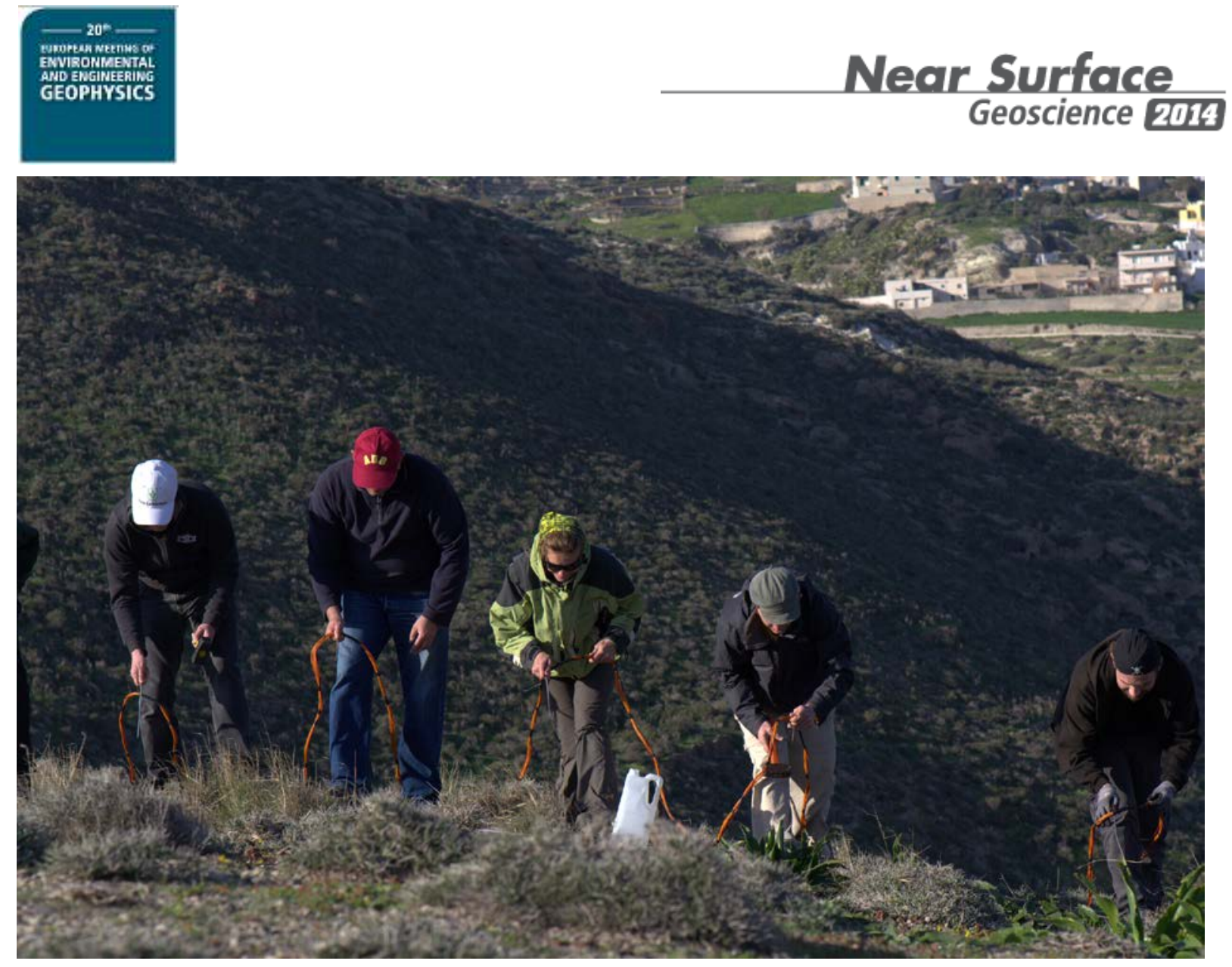

Figure 3 Moving the electrodes on the Red Mountain for Electrical Resistance Tomography measurements. Photo: Geert Verhoeven.

\section{References}

Chouliaras, G., Drakatos, G., Makropoulos, K. and Melis, N. S. [2012] Recent seismicity detection increase in the Santorini volcanic island complex. Nat. Hazards Earth Syst. Sci., 12, 859-866.

Doumas, C. [1983] Thera, Pompeii of the ancient Aegean. Thames and Hudson LtD. London.

Gaffney, C. and Gater, J. [2003] Revealing the buried past: geophysics for archaeologists. Tempus.

Mavor, J. W. [1969] Voyage to Atlantis. G. P. Putnam's Sons, New York.

Russell, J. K. and Stasiuk, M. V. [2000] Ground-penetrating radar mapping of Minoan volcanic deposits and Late Bronze Age palaeotopography, Thera, Greece. In: McGuire, W. G., Griffiths, D. R., Hancock, P. L. and Stewart, I. S. (eds.) The Archaeology of Geological Catastrophes. Geological Society, London, Special Publications, 171, 105-121.

The Thera Foundation [1996] Geoelectrical tomography and ground probing radar (GPR) tests in the archaeological site of Akrotiri in Thera. Piraeus, October 1996.

Vermeule E. [1967] The Promise of Thera. A Bronze Age Pompeii. The Atlantic Monthly, December 1967, 83-94. 